\title{
The Position of Arbitration in Dispute Resolution of Islamic Financial Institutions
}

\author{
Ni Nyoman Adi Astiti ${ }^{1 *}$, Ghozali Rahman', Siti Nur \\ Ibtisamah $^{2}$ \\ ${ }^{1}$ College of Law Tambun Bungai, Palangka Raya, Indonesia \\ ${ }^{2}$ Faculty of Islamic Economics and Business, State Islamic Institute of \\ Palangka Raya \\ *Corresponding author: nyomanadihukum@gmail.com
}

\begin{abstract}
Arbitration in Islamic law is known as the term tahkim which comes from Arabic. Arbitration in Islam has been recognized in the Al-Qur'an, Sunnah and Ijmak. In Indonesia, sharia arbitration focuses on the field of muamalah or sharia-based civil law. Sharia arbitration is very relevant in resolving sharia banking disputes. The practice of tahkim has been done by the companions of the Apostle. Thus, the problems that are resolved by arbitration institutions are not against Islamic law, because Islamic law itself recognizes the legality of arbitration as dispute resolution. However, in the formation of an arbitration institution, elements prohibited by religion should not be included and its decisions are also not contradicting religious law. If a case is related to an arbitration institution to settle it, then according to Islamic law the official judicial institution is no longer authorized.
\end{abstract}

Keywords: arbitration positions, Islamic law, dispute resolution, islamic financial institusions

Cite this article:

Astiti, N.A., Rahman, Ghazali., Ibtisamah, S.N., (2021). The

Position of Arbitration in Dispute Resolution of Islamic Financial

Institutions, Jurnal Al-Qardh, 6(2), 76-83.

https://doi.org/10.23971/jaq.v6i2.3461

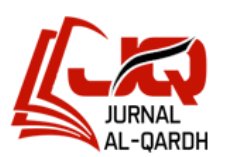

pISSN: $2354-6034$

eISSN: 2599 - 0187

\section{Pendahuluan}

Arbitrase ialah suatu pembahasan tujuan pertanyaan di luar keseluruhan siklus hukum yang diselenggarakan atas kemauan dan keyakinan yang besar, yang dilengkapi dengan pertemuan tanya jawab dengan memberikan pilihan terakhir. Arbitrase memberikan pengaturannya melalui kesempatan pertemuan tanya jawab, dengan tujuan agar mereka dapat membuat hukum dan metodenya sendiri untuk dilaksanakan. ${ }^{1}$ Penyelesaian perdebatan di luar pengadilan negara adalah pilihan pertemuan yang tidak terbatas. Pilihan ini diekspresikan dalam pengaturan tersusun yang dibuat ketika perdebatan terjadi, sesuai dengan aturan peluang kesepakatan dalam common law. ${ }^{2}$ Beberapa sumber membahas keutamaan arbitrase dibanding penyelesaian sengketa melalui proses peradilan. Penyelesaian sengketa jalur pengadilan hanya bersifat formalistik sebab yang bersengketa dipaksa buat menerima ketetapan pengadilan, meskipun keputusan itu dikira tak memenuhi keadilan. Masalah ini merupakan kekhawatiran publik serta dalam ekonomi Islam yang butuh memperoleh atensi.

\footnotetext{
${ }^{1}$ Jefry Tarantang Ni Nyoman Adi Astiti, 'Penyelesaian Sengketa Bisnis Melalui Lembaga Arbitrase', Jurnal AlQardh, 5.2 (2018) < https://doi.org/DOI: https://doi.org/10.23971/jaq.v3i2.1179>.

${ }^{2}$ Yusna Zaidah, 'Lembaga Arbitrase Islam Di Indonesia', Jurnal Hukum, 8.3 (2016).
} 
Oleh karena itu, agar mengantisipasi kekhawatiran ini, Majelis Ulama Indoneisa sudah memprakarsai terbentuknya Badan Arbitrase Muamalat Indonesia yang mana dewasa kini dikenal dengan sebutan Badan Arbitrase Syariah Nasional. ${ }^{3}$ Badan Arbitrase Syariah Nasional ialah salah satu yayasan intervensi yang memiliki posisi untuk menentukan perdebatan bisnis syariah. BASYARNAS memiliki diskresi hukum acara tersendiri yang dijadikan sebagai putusan hukum bagi sidang sebagaimana diatur dalam tata tertib BASYARNAS. Premis sah yang digunakan dalam tujuan debat melalui BASYARNAS adalah aturan Islam dan aturan publik. Peraturan tata cara BASYARNAS mengarahkan premis halal, khususnya dengan mengikuti pada Al-Qur'an, AsSunnah, Ijma, UU No 30 Tahun 1999, Keputusan MUI, serta Fatwa DSN-MUI. ${ }^{4}$

Kehadiran BASYARNAS amat diharapkan oleh umat Islam Indonesia, tidak hanya didorong oleh kesadaran setiap individu menjalankan aturan Islam, tetapi juga menjadi kebutuhan yang nyata. sesuai dengan peningkatan kehidupan moneter dan moneter di antara individu. Maka dari itu, motivasi dibentuknya BASYARNAS adalah sebagai badan tetap yang kapasitasnya menentukan peluang munculnya perdebatan muamalat dalam hubungan pertukaran, bisnis moneter, administrasi dan hal lainnya di kawasan umat Islam. ${ }^{5}$ Mengingat klarifikasi tersebut, penulis tertarik untuk berkonsentrasi pada bagaimana intervensi BASYARNAS dalam hukum Islam, dan bagaimana situasi badan mediasi syariah publik BASYARNAS dalam signifikansinya terhadap penyelesaian perdebatan keuangan Islam.

\section{Metode Penelitian}

Penulisan penelitian ini menggunakan metode normatif melalui literatur kajian pustaka (library research) terhadap buku-buku yang berhubungan dengan tema penelitian yang dibuat, dan juga bersumber dari beberapa penelitian. ${ }^{6}$ Dalam suatu penelitian selalu ada ukuran ragam informasi, yang dalam interaksi ragam informasi akan menggunakan berbagai teknik. Jenis strategi yang dipilih dalam pengumpulan informasi, tentunya harus sesuai dengan sifat dan kualitas pemeriksaan yang di kuasai. Maka pada penelitian ini, penulis memakai metode library research, dan pendekatan syar'i, serta pendekatan yuridis yang akan digunakan dalam pengumpulan datanya. Pendekatan normatif merupakan pendekatan yang mengkaji nilai syariat Islam. Pendekatan ini digunakan sesuai dengan permasalahan yang hendak di teliti, yakni dengan cara meriset bahan pustaka/data sekunder. Sedangkan pendekatan yuridis merupakan pendekatan yang merujuk berdasarkan UU yang sesuai, ataupun data primer terikat bersama peristiwa yang hendak di riset. Dalam metode penelitian kualitatif ini, peneliti menjadi instrumen utama dalam melakukan pengumpulan datanya. Maka, ketika semua data sudah dikumpulkan dengan metode kualitatif ini, diharapkan agar penulis dapat memberikan gambaran/informasi yang mutakhir (up to date) dan jelas, hingga berguna bagi perkembangan ilmu pengetahuan dan bisa diterapkan di berbagai permasalahan terkait dengan alternatif penyelesaian sengketa arbitrase dalam perbankan syariah, dan dalam hukum Islam, yang mana hal ini kemudian akan dianalisis dan dibandingkan berdasarkan teori yang telah ditetapkan.

\section{Literatur Review}

\section{Konsep Arbitrase dalam Hukum Islam}

Pelaku serta pemakai jasa perbankan syariah tentu saja wajib menjalani aktivitasnya menurut prinsip syariah. Apabila terjalin konflik opini baik dalam pengertian ataupun dalam penerapan isi perjanjian, kedua belah pihak hendak berupaya menyelesaikannya dengan cara

\footnotetext{
${ }^{3}$ Yusna Zaidah.

4 Amran Suadi, Peran Pengadilan Dalam Arbitrase Syariah (Jakarta: Kencana, 2018). 45.

${ }^{5}$ Eko Siswanto, 'Peran Arbitrase (BASYARNAS) Dalam Penyelesaian Sengketa Binsis Syari'ah', Jurnal AlAmwal, 3.2 (2018).

${ }^{6}$ Jefry Tarantang, 'Teori Dan Aplikasi Pemikiran Kontemporer Dalam Pembaharuan Hukum Keluarga Islam', Transformatif, 2.1 (2018), 315 <https://doi.org/10.23971/tf.v2i1.882>. 29.
} 
musyawarah, walaupun kemungkinan masih terdapat konflik yang tak bisa dituntaskan dengn cara musyawarah, yang mana hal seperti ini akan kian besar, lebih-lebih didalam kehidupan dunia ekonomi syariah yang berbagai macam. ${ }^{7}$ Pembahasan arbitrase bagi hukum Islam dimaksudkan buat membagikan cerminan kalau di dalam Islam ada metode penanganan konflik semacam arbitrase. Tahkim ialah penunjukan satu orang ataupun lebih sebagai arbiter atau konsiliator oleh 2 orang ataupun lebih yang bersengketa buat menyelesaikan konflik dengan cara musyawarah. ${ }^{8}$

Bagi Abu Al'Ainain Abdul Fatah Muhammad didalam bukunya "Al-Qadha wa Al-Itsbat fi al fiqh Islami" mengemukakan pengertian tahkim ialah bersandarnya 2 orang yang berkonflik ke seseorang yang mereka ridai ketetapannya buat menuntaskan konflik mereka. Penyelesaian sengketa dengan tahkim berarti membuat seseorang sebagai penengah untuk suatu sengketa itu. Maka didefinisikan juga, sebagai suatu penanganan konflik yang dicoba oleh hakam yang diseleksi ataupun ditunjuk dengan cara ikhlas oleh 2 orang yang berseteru diantara mereka serta kedua belah pihak hendak mematuhi penanganan dari hakim ataupun para hakim yang mereka piih tersebut.' Melihat definisi tersebut penulis menyimpulkan, kalau arbitrase didalam Islam disebut dengan istilah tahkim yang berarti cara penyelesaian yang berada di luar pengadilan perselisihan diantara kedua belah pihak yang bersengketa, serta bersifat privat. Perselisihan yang terjadi tentag hak milik maupun hak-hak lainnya yang diselesaikan dengan lewat bantuan pihak ketiga ataupun wasit. Keamanan dari dua pertemuan tanya jawab kepada individu yang mereka pilih (sebagai perantara) untuk memilih perdebatan di antara mereka, dan kedua orang yang bersengketa tersebut telah sepakat dan ikhlas menerima keputusan dari pihak ketiga.

\section{Dasar Hukum Arbitrase Syariah}

Semua aktivitas didalam ajaran Islam harus berlandaskan aturan yang sudah diputuskan didalam Al-Qur'an, Sunnah, ataupun hasil ijtihad. Badan Arbitrase amat disarankan didalam Islam, karena digunakan untuk menggapai kemufakatan yang maslahah dalam penanganan suatu konflik bermacam aspek kehidupan tercantum sengketa-sengketa dalam aspek muamalah. Perihal ini dimaksudkan supaya pemeluk Islam bebas dari konflik yang bisa memperlemah aliansi serta kesatuan persaudaraan Islamiyah. ${ }^{10}$ Dasar pemberlakuan lembaga arbitrase dalam Islam berlandaskan kepada Al-Qur'an, sebagaimana firman Allah Subhanabu wa Ta'ala yang terdapat didalam Surah An-Nisa Ayat 35. ${ }^{11}$ Selain itu, dasar hukum bagi keharusan bertahkim juga dianjuran dalam Al-Qur'an mengenai butuhnya perdamaian, yakni dalam Surah Al-Hujurat Ayat 9. Berdasarkan ayat ini disebut bahwa, bila salah satu diantaranya melaksanakan pelanggaran, hingga wajib diberikan ganjaran dengan jalur usaha menuntut. Apabila pelanggaran itu memilki angka eksekutorial, hingga wajib dicoba usaha menuntut cocok dengan akad para pihak ataupun putusan Badan Arbitrase, bagus tetapan tunggal ataupun majelis. Maka dari pernyatan ini dapat disimpulkan bahwa, keharusan untuk berlaku adil dalam menuntaskan sengketa kedua belah pihak, berhubungan dengan kerugian yang dirasakan oleh salah satu pihak dampak kelakuan pihak yang lain, ialah putuskanlah perihal itu dengan adil serta bijak. ${ }^{12}$

\footnotetext{
7 Warkum Sumitro, Asas-Asas Perbankan Islam Dan Lembaga-Lembaga Terkait (BAMUI \& TAKAFUL) Di Indonesia (Jakarta: PT. Raja Grafindo Persada, 1997). 149.

${ }^{8}$ Sanwiah, 'Badan Arbitrase Syari'ah Nasional (BASYARNAS) Menyelesaikan Sengketa Secara Adil Dan Cepat', Jurnal Anterior, 12.2 (2013). 105.

${ }^{9}$ Suhrawardi, Hukum Ekonomi Islam (Jakarta: Sinar Grafika, 2004). 186.

10 Ummi Uzma, 'Pelaksanaan Atau Eksekusi Putusan Badan Arbitrase Syariah Nasional (BASYARNAS)

Sebagai Kewenangan Pengadilan Agama', Jurnal Hukum Dan Pembangunan, 4.3 (2014).

${ }^{11}$ Waldi Nopriansyah, Hukum Bisnis Di Indonesia (Jakarta: Prenadamedia Group, 2019). 234.

12 Abdullah bin Muhammad bin Abdurahman bin Ishaq Al-Sheikh, Tafsir Ibnu Katsir Jilid 2 (Bogor: Pustaka Imam Asy-Syafi'i, 2003). 481.
} 
Apabila ditinjau dari dasar hukumnya dalam As-Sunah, hadits Nabi di riwayatkan oleh Imam al-Tirmidzi dari Amr bin Auf al-Muzani, Nabi Muhammad bersabda, "Perjanjian boleh serta bebas dilaksanakan diantara umat muslimin kecuali perjanjian yang mengharamkan yang halal ataupun menghalalkan yang haram, serta umat muslimin terikat dengan kriteria mereka kecuali kriteria yang mengharamkan yang halal ataupun menghalalkan yang haram". Tidak hanya pondasi hukum arbitrase yang berasal dari Al-Qur'an serta Sunnah, dasar hukum arbitrase pula berasal dari hukum ijtihad dalam memutuskan hukum kepada suatu yang dibuat dasar hukum Islam. Didalam memo asal usul Islam, kehadiran lembaga tahkim pada era sahabat banyak dilaksanakan tanpa adanya pertentangan. Seperti pernyataan Sayyididna Umar Ibnu Khatab kalau, "Tolaklah permusuhan bingga mereka berdamai, karena pemutusan perkara melalui pengadilan akan mengembangkan kedengkian di antara mereka". Dan ini juga diatur dalam UU No 48 Tahun 2009. ${ }^{13}$

Arbitrase Indonesia juga telah dikelola didalam Undang-undang Nomor 30 Tahun 1999 tentang Arbitrase dan Alternatif Penyelesaian Sengketa dan Pasal 1 Pasal 1 UndangUndang Nomor 30 Tahun 1999 menetapkan pengertian arbitrase, yaitu menyelesaikan sengketa perdata di luar pengadilan biasa sesuai dengan perjanjian arbitrase yang dibuat oleh majelis arbitrase. lembaga arbitrase secara tertulis sengketa. Pihak yang berkepentingan. ${ }^{14}$ Selain dari Al-Qur'an, Hadis, dan ijma ulama dari kelompok sahabat Rasulullah atas kesahan praktik tahkim, di era kawan sudah terjalin segketa dengan cara arbitrase di golongan para kawan serta tidak seseorang juga yang menentangnya. Ada pula sebagian opini dari ahli pakar hukum mengenai berartinya kehadiran Arbitrase Syariah, sebagai berikut:

a. Sayyid Sabiq, ${ }^{15}$ kalau memperhatikan pengaturan berdasarkan Islam adalah wajib, melihat dampak positifnya serta tugasnya yang besar dalam menjaga kerukunan dan melihat beratnya dalam mengalahkan kesulitan, menyelesaikan pertanyaan serta membuat kerukunan.

b. H. Hartono Mardjono, ${ }^{16}$ bahwa kehadiran organisasi yang menderita, kemampuan apa untuk memutuskan peluang pertanyaan normal antara bank syariah dan pelanggan mereka, khususnya yang menggunakan organisasi mereka, untuk sebagian besar antara orang-orang Muslim yang menyelesaikan hubungan normal yang didasarkan pada syariah ialah keperluan yang nyata.

c. Rachmadi Usman, ${ }^{17}$ kalau pembentukan badan intervensi yang bergantung pada hukum Islam diundang dengan penuh semangat oleh berbagai pertemuan, bukan hanya karena kesadaran dan keinginan individu yang tak terhindarkan terhadap pelaksanaan hukum Islam, tetapi juga didorong oleh persyaratan yang tulus untuk tindakan keadilan bersama. secara damai sesuai dengan perbaikan ekonomi moneter di golongan umat Islam.

d. H. Pranowo Gandasubrata, ${ }^{18}$ bahwa hukum kadang-kadang terasa tanpa ampun atau kaku, dengan alasan bahwa hukum adalah untuk keyakinan yang sah untuk diterapkan, namun melalui penegasan, sisi kejam dari penggunaan hukum dapat diliputi oleh pemanfaatan musyarwarah dan kesepakatan dengan Islam.

\footnotetext{
13 Undang-Undang Nomor 48 Tahun 2009, Tentang Kekuasaan Kehakiman.

${ }^{14}$ Undang-Undang Nomor 30 Tabun 1999, Tentang Arbitrase Dan Alternatif Penyelesaian Sengketa.

${ }^{15}$ Sayyid Sabiq, Fikih Sunnah 11 (Bandung: PT. Alma'Arif, 1980). 173.

${ }^{16}$ H. Hartono Mardjono, Menegakan Syariat Islam Dalam Konteks Ke Indonesiaan I (Bandung: Mizan, 1981). 66.

${ }^{17}$ Rachmadi Usman, Hukum Ekonomi Dalam Dinamika (Jakarta: Djambatan, 2000). 100.

${ }_{18}$ Badan Arbitrase Muamalat Indonesia (B AMUI), Sambutan Ketua Mabkamah Agung Republik Indonesia Pada Peresmian

Badan Arbitrase Muamalat Indonesia, Badan Arbitrase Muamalat Indonesia (BAMUI) (Jakarta, 1994). 10.
} 


\section{Pembahasan}

\section{Sejarah Perkembangan Badan Arbitrase Syariah Nasional}

Arbitrase dicirikan oleh istilah tahkim, yang secara etimologis bermaksud membuat seseorang sebagai penghalang perdebatan. Pendirian ini sudah dikenal dari zaman pra-Islam, yang mana di kala itu belum ada kerangka hukum yang terkoordinasi, dan sering ada pertanyaan tentang hak-hak warisan serta hak lain yang dituntaskan lewat bantuan juru damai/pejabat yang dipilih oleh pertemuan-pertemuan tanya jawab. ${ }^{19}$ Didirikannya mediasi Islam di Indonesia dimulai berkumpulnya pakar, peneliti islam, ahli hukum, kyai, serta ulama untuk memecahkan masalah dengan berbagi pikiran mengenai pentingnya organisasi arbitrase di Indonesia. Silaturahmi ini digeser oleh Majelis Ulama Indonesia di 22 April 1992. Sesudah diadakan banyak pertemuan untuk menyempurnakan draf desain hierarki dan teknik prosedural, pada 23 Oktober 1993 dibentuk BAMUI, dan berubah nama jadi BASYARNAS, yang disepakati didalam Rakernas MUI tahun 2002. ${ }^{20}$

Pilihan Panitia Tata Usaha MUI No: Kep 09/MUI/XII/2003 di 24 Desember 2003, nama BAMUI dirubah jadi BASYARNAS, diusulkan dari hasil RAKERNAS MUI di 23 sampai 26 Desember 2002. Persatuan MUI BASYARNAS berdiri dengan pemerintahan sendiri sebagai instrumen yang sah yang menyelesaikan pertanyaan antara pihak, baik individu yang datang sangat dekat dengan bank syariah, perlindungan Islam dan pertemuan yang membutuhkannya. ${ }^{21}$ Kehadiran BASYARNAS diperlukan oleh umat Islam Indonesia, tidak hanya didorong oleh kesadaran individu untuk menjalankan syariat Islam, tetapi lebih dari itu adalah kebutuhan yang sesuai dengan kemajuan ekonomi dan keuangan. kehidupan moneter di antara individu. Oleh karena itu, motivasi di balik pendirian BASYARNAS sebagai badan yang langgeng dan otonom adalah untuk mengetahui peluang munculnya persoalan muamalat dalam hubungan pertukaran, bisnis moneter, administrasi dan lain-lain di kalangan umat Islam. ${ }^{22}$

Maka dapat diketahui bahwa, terdapatnya BASYARNAS sebagai suatu lembaga permanen yang berperan buat menuntaskan kemungkianan terbentuknya bentrokan awas diantara bank syariah dengan para konsumennya, ataupun para konsumen pelayanan mereka pada khususunya, serta diantara sesama pemeluk Islam yang melaksanakan ikatan keperdataan yang menghasilkan syariah Islam sebagai dasarnya. Dengan adanya fatwa DSN, setiap produk akad bank syariah maupun lembaga keuangan syariah wajib melampirkan klausula arbitrase, sehingga seluruh sengketa yang berlangsung diantara perbankan syariah dengan konsumennya, sengketa tersebut wajib diselesaikan lewat BASYARNAS. ${ }^{23}$

\section{Kelembagaan Arbitrase Nasional dan Internasional Menurut Hukum Islam}

Landasan pembentukan arbitrase tidak diragukan lagi, hal ini merupakan pengakuan terhadap gagasan hukum Islam dalam hal mediasi. Sejalan dengan itu, MUI membentuk badan arbitrase yang diberi nama BAMUI, di mana pengaturan pendirian penegasan tidak boleh mengandung komponen yang menyalahgunakan pengaturan dalam hukum Islam. Misalnya, pembentukan arbitrase menetapkan suatu syarat bahwa untuk menyelesaikan suatu perkara melalui badan mediasi, seseorang harus melakukan hal-hal yang diharamkan oleh

\footnotetext{
19 Darwinsyah Minin, 'Penyelesaian Sengketa Dalam Praktik Ekonomi Syariah Di Luar Pengadilan Menurut Hukum Islam’, Jurnal Ilmu Hukum, 2.2 (2019).

${ }^{20}$ A. Rahmat Rosyadi, Arbitrase Dalam Perspektif Islam Dan Hukum Positif (Jakarta: Citra Aditya Bakti, 2002). 43.

${ }^{21}$ Rosyadi. 132.

22 Ridzky Adityanto, 'Kedudukan Basyarnas Dalam Penyelesaian Sengketa Perbankan Syariah (Studi Putusan Mahkamah Konstitusi Nomor 93/PUU-X/2012)', Jurnal LamLaj, 1.2 (2016).

23 Ahmad Dimiyati, Sejarah Lahirnya BAMUI Dalam Arbitrase Islam Di Indonesia (Jakarta: Rineka Cipta, 2005). 191.
} 
agama, maka pada saat itu hal tersebut jelas tidak akan didukung. ${ }^{24}$ Dalam hukum Islam, semua tindakan yang bersifat muamalat ialah boleh kecuali terdapat dalil yang melarangnya. Sebagaimana sesuai dengan aturan ushul fikih yang bunyinya "Segala yang sesuai dalam bidang muamalah pada dasarnya adalab boleh hingga ada dalil yong melarang". Arbitrase mempunyai landasan hukum yang kuat dari hukum Islam, maka pembentukan lembaga arbitrase yang sifat nasional maupun internasional adalah boleh, dengan catatan selama di dalamnya tidak terdapat unsur yang terlarang menurut agama, dan putusannya tidak bertentangan dengan hukum agama. ${ }^{25}$

\section{Syarat-Syarat dan Putusan Badan Arbitrase}

Ada beberapa syarat yang dirumuskan oleh sebagian ulama, berkaitan dengan pelaksanaan tahkim. Syarat-syarat tersebut ialah:

1) Perkumpulan-perkumpulan yang melakukan perbuatan tahkim, baik sebagai hakim (penguasa), pihak yang dirugikan, maupun responden harus diperlengkapi untuk bertindak, setiap perkumpulan berhak dan layak untuk bertindak menurut hukum.

2) Perkumpulan, dua pejabat yang ditunjuk, orang yang dirugikan dan yang berperkara untuk klasifikasi memiliki kemampuan sebagai saksi.

3) Cara pelaksanaan tahkim atau interaksi pendahuluan pertanyaan diskresi diarahkan oleh standar "waqt al-tahkim wa al-bukm", khususnya kesamaan antara kepastian pilihan hakim dan pelaksanaan pilihannya.

4) Pihak yang besengketa saat menunjuk hakam wajib jelas serta pasti. ${ }^{26}$

Putusan Badan Arbitrase, Persetujuan para pihak akar dari penanganan konflik lewat rute tahkim Ini adalah pencapaian perdamaian dari pihak-pihak yang bertikai. Perdamaian termasuk dalam kontrak yang ditandatangani oleh pihak-pihak yang bertikai, sehingga perjanjian damai mengikat secara hukum kedua belah pihak. Namun, terkadang tidak ada pihak yang dapat memperoleh keputusan arbiter, atau ditolak setelah hari arbiter membuat keputusan. ${ }^{27}$ Para ahli hukum Islam tradisional membandingkan situasi tersebut dengan pilihan hakim. Pertama-tama, sebagian besar peneliti dari mazhab Hanafi, Malik, dan Hanbali menilai bahwa pilihan otoritas yang ditunjuk adalah yang tertinggi untuk pertemuan tanya jawab. Pilihan bersifat pasti dan membatasi pertemuan, sehingga tidak ada alasan untuk salah satu majelis buat membubarkannya. Kedua, peneliti dari mazhab Syafi'i menilai kalau pilihan otoritas yang ditunjuk tidak membatasi dua pemain pada pertanyaan, jika salah satu majelis tidak mau dan menolak pilihan. Penjelasannya, pilihan tahkim itu seperti konsekuensi dari sebuah fatwa, cenderung diakui dan cenderung ditolak. ${ }^{28}$

\section{Relevansi Arbitrase Islam dalam Penyelesaian Sengketa Perbankan Syariah}

Diperkenalkannya UU No 21 Tahun 2008 mengenai Perbankan Syariah membawa iklim segar bagi pedoman perbankan syariah di Indonesia. UU tersebut sudah memisahkan perbankan syariah dengan cara otonom dari rencana keuangan tradisional seperti yang terjadi di bawah pengawasan yang khususnya di bawah UU No 7 Tahun 1992 mengenai Perbankan yang setelah itu digantikan dengan UU No 10 Tahun 1998. UU No 21 Tahun 2008 mempunyai beberapa tujuan mendasar sebagai berikut: ${ }^{29}$

\footnotetext{
${ }^{24}$ Abdul Manan, Hukum Ekonomi Syari'ah Dalam PerspektifKewenangan Peradilan Agama (Jakarta: Kencana Prenada Media Group, 2014). 461.

25 Zainal Arifin, ‘Arbitrase Dalam Perspektif Hukum Islam’, Jurnal Artikel, 7.18 (2006). 78.

${ }^{26}$ Muhammad Rusli, Arbitrase Syariah Formalisasi Hukum Islam Dalam Ranah Penyelesaian Sengketa Ekonomi Syariah Secara Non Litigasi (Parepare: Trust Media Publishing, 2017). 29.

${ }^{27}$ Rusli. 32.

${ }^{28}$ Rusli. 30-31

${ }^{29}$ Muhammad Arifin, 'Arbitrase Dalam Hukum Islam Dan Relevansinya Bagi Penyelesaian Sengketa Perbankan Syariah', Jurnal Spektrum, 11.1 (2014). 33.
} 
a. Menjamin konsistensi syariah yang tercermin dalam pengaturan bisnis yang tak berlawanan dengan standar syariah, pengesahan otoritas fatwa syariah oleh MUI.

b. Menjamin kekokohan kerangka moneter yang terlihat dari pemilihan Center Standards for Powerfull Financial Oversight, seperti yayasan dan kepemilikan, mengendalikan investor, administrasi, standar kehati-hatian, membahayakan komitmen eksekutif serta pelatihan dan manajemen. ${ }^{30}$

Perjanjian khusus ini akan memberikan ide tentang keaslian kebijaksanaan Islam yang benar-benar memiliki tempat sebagai pilihan tingkat pertemuan menuju pertanyaan keuangan Islam. Kondisi mediasi syariah sebagai pilihan alternatif dengan pengadilan yang berat tetap signifikan dalam menyelesaikan masalah perbankan syariah. Dengan berbagai keuntungan intervensi syariah, dapat dibayangkan sebagai kemajuan yang efektif sebagai tujuan diskusi yang lebih bermanfaat dan menarik. Sepenuhnya berniat mengajukan pertanyaan yang menyenangkan, sehingga asosiasi dipertahankan dan menghasilkan tantangan kuat yang sebagian besar bermanfaat untuk hal hebat. ${ }^{31}$

\section{Kesimpulan}

Dilihat dari data masa lalu, cenderung beralasan bahwa kehadiran mediasi dan itu tidak lain adalah posisi yang kokoh bagi hukum. Istilah tahkim memiliki definisi yang hampir sama dengan penegasan. Tahkim dalam pemikiran syariat Islam diharapkan dapat mengatasi masalah keluarga, namun tidak memiliki pengaruh yang signifikan secara kaku. Hukum Islam mengizinkan semua jenis muamalah, selama tidak ada bukti yang melarangnya. Dengan demikian, seorang Muslim dapat menyelesaikan kasusnya melalui landasan intervensi yang layak. Spesialis kontras seperti yang mereka lihat dalam mengevaluasi kekuatan pengadilan untuk menengahi perdebatan yang telah terikat dalam pengaturan diskresi. Pertemuan utama menyatakan bahwa pengadilan sebenarnya memiliki kekuatan untuk menyelesaikan kasus yang diperebutkan, dalam hal satu atau dua pemain mengajukan perdebatan ke pengadilan.

Sejalan dengan itu, situasi arbitrase syariah sebagai pilihan yang kontras dengan pengadilan yang ketat tetap penting dalam menyelesaikan pertanyaan perbankan syariah, dengan berbagai manfaat yang dimiliki oleh diskresi Islami, maka cenderung menjadi peluang untuk musyawarah sebagai tempat diskusi untuk tujuan pertanyaan yang lebih cakap dan berhasil. Gagasan tujuan debat yang bermanfaat, mediasi syariah dapat menyelesaikan pertanyaan dengan kesepakatan, sehingga hubungan yang baik tetap terjaga yang dengan demikian menciptakan kontes suara yang umumnya bermanfaat dalam kebaikan.

\section{Saran}

Seiring dengan peningkatan ekonomi syariah yang tak dapat dipisahkan dari segala potensi pertanyaan didalam tiap pelaksanaan bisnisnya, peran BASYARNAS sebagai yayasan penyelesaian perdebatan keuangan syariah di luar pengadilan hendak makin meningkat. Dengan demikian, BASYARNAS wajib melaksanakan lompatan ke depan serta usaha perbaikan kerangka kerja yang lain. Kemudian, untuk menjamin kepastian hukum, diperlukan harmonisasi vertikal pengaturan hukum, sebagai alasan pelaksanaan pilihan BASYARNAS.

\section{Daftar Pustaka}

Adityanto, Ridzky, 'Kedudukan Basyarnas Dalam Penyelesaian Sengketa Perbankan Syariah (Studi Putusan Mahkamah Konstitusi Nomor 93/PUU-X/2012)', Jurnal LamLaj, 1.2 (2016)

Al-Sheikh, Abdullah bin Muhammad bin Abdurahman bin Ishaq, Tafsir Ibnu Katsir Jilid 2

\footnotetext{
${ }^{30}$ Yusuf Wibisono, Indonesia Shariah Economic Outlook (ISEO) (Jakarta: Lembaga Penerbit Fakultas Ekonomi, 2011). 3.

${ }_{31}$ Mohammad Daud Ali, Hukum Islam: Pengantar Ilmu Hukum Dan Tata Hukum Islam Di Indonesia (Jakarta: PT Raja Grafindo Persada, 2000). 14.
} 
(Bogor: Pustaka Imam Asy-Syafi'i, 2003)

Ali, Mohammad Daud, Hukum Islam: Pengantar Ilmu Hukum Dan Tata Hukum Islam Di Indonesia (Jakarta: PT Raja Grafindo Persada, 2000)

Arifin, Muhammad, 'Arbitrase Dalam Hukum Islam Dan Relevansinya Bagi Penyelesaian Sengketa Perbankan Syariah', Jurnal Spektrum, 11.1 (2014)

Arifin, Zainal, 'Arbitrase Dalam Perspektif Hukum Islam', Jurnal Artikel, 7.18 (2006)

Badan Arbitrase Muamalat Indonesia (BAMUI), Sambutan Ketua Mabkamab Agung Republik Indonesia Pada Peresmian Badan Arbitrase Muamalat Indonesia, Badan Arbitrase Muamalat Indonesia (BAMUI) (Jakarta, 1994)

Dimiyati, Ahmad, Sejarah Labirnya BAMUI Dalam Arbitrase Islam Di Indonesia (Jakarta: Rineka Cipta, 2005)

Manan, Abdul, Hukum Ekonomi Syari'ah Dalam Perspektif Kewenangan Peradilan Agama (Jakarta: Kencana Prenada Media Group, 2014)

Mardjono, H. Hartono, Menegakan Syariat Islam Dalam Konteks Ke Indonesiaan I (Bandung: Mizan, 1981)

Minin, Darwinsyah, 'Penyelesaian Sengketa Dalam Praktik Ekonomi Syariah Di Luar Pengadilan Menurut Hukum Islam', Jurnal Ilmu Hukum, 2.2 (2019)

Ni Nyoman Adi Astiti, Jefry Tarantang, 'Penyelesaian Sengketa Bisnis Melalui Lembaga Arbitrase', Jurnal Al-Qardh, $5.2 \quad$ (2018) <https://doi.org/DOI: https://doi.org/10.23971/jaq.v3i2.1179>

Nopriansyah, Waldi, Hukum Bisnis Di Indonesia (Jakarta: Prenadamedia Group, 2019)

Rosyadi, A. Rahmat, Arbitrase Dalam Perspektif Islam Dan Hukum Positif (Jakarta: Citra Aditya Bakti, 2002)

Rusli, Muhammad, Arbitrase Syariah Formalisasi Hukum Islam Dalam Ranah Penyelesaian Sengketa Ekonomi Syariah Secara Non Litigasi (Parepare: Trust Media Publishing, 2017)

Sabiq, Sayyid, Fikih Sunnah 11 (Bandung: PT. Alma'Arif, 1980)

Sanwiah, 'Badan Arbitrase Syari'ah Nasional (BASYARNAS) Menyelesaikan Sengketa Secara Adil Dan Cepat', Jurnal Anterior, 12.2 (2013)

Siswanto, Eko, 'Peran Arbitrase (BASYARNAS) Dalam Penyelesaian Sengketa Binsis Syari'ah', Jurnal Al-Amwal, 3.2 (2018)

Suadi, Amran, Peran Pengadilan Dalam Arbitrase Syariah (Jakarta: Kencana, 2018)

Suhrawardi, Hukum Ekonomi Islam (Jakarta: Sinar Grafika, 2004)

Sumitro, Warkum, Asas-Asas Perbankan Islam Dan Lembaga-Lembaga Terkait (BAMUI \& TAKAFUL) Di Indonesia (Jakarta: PT. Raja Grafindo Persada, 1997)

Tarantang, Jefry, 'Teori Dan Aplikasi Pemikiran Kontemporer Dalam Pembaharuan Hukum

Keluarga Islam', Transformatif, 2.1 (2018), 315 <https://doi.org/10.23971/tf.v2i1.882>

Undang-Undang Nomor 30 Tabun 1999, Tentang Arbitrase Dan Alternatif Penyelesaian Sengketa

Undang-Undang Nomor 48 Tabun 2009, Tentang Kekuasaan Kehakiman

Usman, Rachmadi, Hukum Ekonomi Dalam Dinamika (Jakarta: Djambatan, 2000)

Uzma, Ummi, 'Pelaksanaan Atau Eksekusi Putusan Badan Arbitrase Syariah Nasional (BASYARNAS) Sebagai Kewenangan Pengadilan Agama', Jurnal Hukum Dan Pembangunan, 4.3 (2014)

Wibisono, Yusuf, Indonesia Shariah Economic Outlook (ISEO) (Jakarta: Lembaga Penerbit Fakultas Ekonomi, 2011)

Yusna Zaidah, 'Lembaga Arbitrase Islam Di Indonesia', Jurnal Hukum, 8.3 (2016) 